\title{
COLLABORATIVE TAKT TIME PLANNING OF NON-REPETITIVE WORK
}

\author{
Iris D. Tommelein ${ }^{1}$
}

\begin{abstract}
This paper describes an approach for takt time planning (TTP) that was developed and tested on a pilot project in California. A companion paper by other authors describes their approach for TTP that they applied in a different project type-, commercial-, and geographical context. The aim of these papers is to articulate TTP methods used so as to allow for comparison, refinement, and improvement.

The here-described approach was piloted on the gut-and-remodel of a small healthcare project. The owner chose to deliver this project using an Integrated Form of Agreement (IFOA) contract. Accordingly, the project team members working together as trade partners were driven to explore opportunities to use lean practices.

The researchers offered the IFOA team an action research opportunity to study together, not so much if-, but rather how takt time might be used to plan and execute their work because, at first glance, units of repetitive work were not obvious. The researchers embedded with the team developed a TTP approach on the basis of "work density" and then successfully used it on two project phases.

The contribution of this paper is that it presents a characterization and proposes a formalization of a method for collaborative TTP of non-repetitive work. This may inform the use of TTP on other projects, as well as serve as a basis for comparing and contrasting takt time- and other planning methods.
\end{abstract}

Keywords: Lean construction, collaborative planning, takt time planning (TTP), work structuring, work density, Last Planner System (LPS)

\section{INTRODUCTION}

Takt is increasingly being used to structure construction work and thus "shape" schedules of work anticipated and control of work being executed (e.g., Linnik et al. 2013). Use of takt imposes a rationale and methodological structure that aims to achieve continuous flow in the schedule. This is done by using capacity buffers and defining clearly delineated handoffs between trades, thus marking schedule control points that can help increase predictability in system performance.

This paper details a takt time planning (TTP) method for work structuring that was piloted on a project in the San Francisco Bay Area. A companion paper (Binninger et al. 2017) describes a takt planning method in use in Germany. In subsequent work, the authors of these papers will present a framework for characterization of takt planning methods, and illustrate its use in comparing their methods as described. Frandson et al. (2015) already compared TTP with Location Based Management (LBMS). Further comparison of these and other planning methods is warranted.

The word "Takt" or "Taktzeit" in German means "beat," the regularity with which something gets done. Since "Takt" in German, like "beat" in English, by definition pertains to time, saying "takt time" is redundant; this notwithstanding, the latter is commonly said.

Professor, Engrg. and Project Mgmt. Program, Civil and Envir. Engrg. Dept., Director, Project Production Systems Lab., University of California, Berkeley, CA, USA, tommelein@berkeley.edu 
When takt is used in a lean context, it is interlinked with many other lean concepts, such as continuous flow, standardization, load leveling, predictability, etc. Takt refers to the heartbeat of assembly lines in the Toyota Production System. Once a beat is suited to each line and set (different lines each having their own beat), lines can move in sync with one another in a continuous flow process. Whether at Toyota, in new product development and manufacturing at large, or in construction, takt may be defined as: the unit of time within which a unit of production must be produced (supply rate) in order to match the rate at which that product is needed by the customer (demand rate) (after Hopp and Spearman 2011 p. 467-468). So-defined, takt is a design parameter that may be used in production in manufacturing, construction, or any other setting.

The approaches used in industry today and conceptualizations of the use of takt appear to vary. With this paper and ongoing study the author aims to create conceptual clarity and highlight distinctions between takt planning methods and the contexts in which they apply. This paper lays out methodological steps, based on the fundamental concept called "work density," used to define takt in a production system's design. These steps detail the method for collaborative TTP of non-repetitive work that the researchers developed and piloted while embedded with a team delivering a small project in California.

\section{TTP Rooted IN SPACE SCHEDULING}

The author's study of TTP is rooted in her research on "space scheduling" (Tommelein and Zouein 1993 p. 266) that stemmed from the observation that the resource "space" is omnipresent yet-paradoxically-often overlooked in construction management. Many of today's construction management books still consider only 5 resources (i.e., time, money, manpower, machines, and materials) and overlook space. Yet, space is the $6^{\text {th }}$ resource to be managed, not only in the process of layout planning (e.g., while locating temporary facilities such as material laydown yards and equipment) but also of scheduling. Line-ofBalance methods (LOB) (e.g., Lumsden 1968) to plan production of repetitive units, tend to treat space as a scalar (1D) variable and thereby abstract away significant complexity encountered when managing 2D or 3D space (e.g., Riley and Sanvido (1995) studied patterns of flow). With the advent of computer tools such as BIM, space has become more "visible" and easier to draw management attention to. Many software tools exist today to show in 3D and simulate in 4D how site space use in and around the facility being built evolves during construction (e.g., Navisworks, Synchro). TTP is a kind of space scheduling.

After describing the context of the pilot project, we present the rationale and methodological structure of the approach we used to shape this project's construction space schedule on the basis of takt.

\section{Geographical AND PRoject CONTEXT}

We developed the here-described approach for collaborative TTP on a $700 \mathrm{~m}^{2}\left(7,500 \mathrm{ft}^{2}\right)$ gut-and-remodel healthcare project. This project, located in the San Francisco Bay Area, was constructed over the course of about 12 months in 2012-2013 at a cost of about USD 3 million (Dunnebier et al. 2014). The owner, Sutter Health, chose to deliver this project using an Integrated Form of Agreement (IFOA) contract. Jointly with the owner, designer, and general contractor (GC), the IFOA project team comprised specialty contractors, several of which had previously worked together on other projects. Team members were thus driven to collaboratively explore opportunities for using lean practices. 
The researchers, Iris Tommelein and graduate students-in early planning of the project Josh Mohayai and soon thereafter Adam Frandson-offered the IFOA team an action research opportunity to study together, not so much if-, but rather how takt time might be used to plan and execute their work because, at first glance, units of repetitive work were not obvious. The researchers embedded with the team ended up developing an approach and successfully using it on two out of four project phases, namely above-ceiling work and in-wall work (Frandson and Tommelein 2014).

The project scope included demolishing the existing interior of about half a floor in the facility and then constructing a new interior. The work was planned in phases: (1) demolition, (2) framing and above-ceiling work, (3) in-wall work, and (4) finishes. All work had to be done while maintaining the structure as well as the live fire sprinkler system, and maintaining full operation of the remainder of the facility. This constrained site access, forced some work to be done at night, and restricted some day-time work (e.g., drilling to mount anchors in concrete floor slabs was permitted only at certain times so as to not disturb healthcare providers and patients during their business hours).

\section{THEORETICAL FormULATION}

\subsection{Takt Time in Manufacturing vs Takt Time in Construction}

While in manufacturing, the assembly line for the product being built keeps moving and workers are more-or-less stationary (nevertheless moving with the line while performing their task), in construction, the product (facility) being constructed is stationary and workers move from one location to another to perform their task in situ.

The speed of the line and the corresponding rate of work at stations must be designed so that each worker at each station can complete what is assigned to them and still have some time left within the takt time given. Under ideal circumstances, each station's task will be reliably $100 \%$ done within the allotted takt. Of course, in a world subject to variation, one can never be $100 \%$ sure so when a deviation from the standard task occurs, the "time left" serves as a capacity buffer. This buffer ensures that each worker has some time remaining within their takt, in case they notice a condition that warrants pulling the andon for others to come to their assistance, and address the condition without having to stop the line. Determining the appropriate task to be done at each station and thus the capacity buffer is key to the production system's design, because when the "time left" is insufficient, workers must stop the line to manage the situation.

Translated from manufacturing to construction, TTP seeks to define spaces (we call these spaces that are tied to a takt time "zones") in a facility as it is being constructed so that each trade can get their work reliably done in each zone, according to their planned sequence of work, in an amount of time (takt) that is the same for all trades who need to work in that zone. Just like a line's takt will likely vary from other lines' in a single manufacturing plant according to the tasks performed at the various stations in each line, takt and the corresponding zones will likely vary from one phase of construction to another on the same project.

\subsection{Takt Time Planning is a Work Structuring Method}

Generally speaking, TTP is a work structuring method. Work structuring means breaking an entire project into smaller pieces (so-called "chunks") so that these pieces will be manageable. Ballard (1999), Ballard et al. (2001), and Tsao et al. (2004) defined work structuring as addressing the following questions: 
1. In what units (chunks) will work be assigned to production units?

2. How will work chunks be sequenced?

3. How will work be released from one production unit to the next?

4. Will consecutive production units execute work in a continuous flow process or will their work be decoupled?

5. Where will decoupling buffers be needed and how should they be sized?

6. When will the different chunks of work be done?

Manageability of the pieces may be assessed based on the degree to which certain production system objectives are met. Structuring of work using TPP has as objectives:

1. Have trades work in a way they prefer.

2. Aim for constant crew sizes and continuous work flow (i.e., no work interruptions).

3. Avoid trade stacking (i.e., only 1 trade works in any 1 zone at any time).

4. Use timely on-takt handoffs.

5. Balance the whole while pushing for speed.

\subsection{Finding Repetition in Non-Repetitive Work based on Work Density}

Answers to the work structuring questions will affect the various production system parameters that act as throttles in the system. These parameters pertain to the product to be constructed and to the process (means and methods) used for construction, namely:

1. Components and characteristics of the product to be constructed, describing the work to be done as typically shown in plans and specifications, perhaps in a BIM.

2. Worker trade skills, informing what work can be done by an individual worker (e.g., a specific journeyman or apprentice) or crew that will be designated in the weekly work plan to complete an assignment.

3. Alternative breakdowns of the scope of work, e.g., by trade (boundaries of work between trades, based on union jurisdictions or other drivers) and sequence.

4. Alternative means and methods available to each trade to do their work.

5. The number of trade resources that can be assigned when using specific means and methods, and corresponding space and time needed to complete work.

The setting of these parameters defines chunks of work and how they will flow or not (e.g., when decoupling buffers are added). A chunk is work of a certain scope that will be performed by a crew of a certain configuration (number of crew members and their individual and combined skills), using certain means and methods. Aiming to meet the stated objectives, the goal pursued in TTP is to define chunks to be done in certain locations (zones), so that all chunks can be performed in the same amount of time (takt) and in a sequence that emulates continuous flow.

An ideal flow may present itself as a Parade of Trades (Tommelein et al. 1999) moving through space with one trade following the other in sequence, all marching to a drum beat, and-ideally-with no variability. However, it is unlikely that all construction work can be cast in such a mold. If it can be, then creating a TTP is relatively straightforward, but how to develop a TTP when work is not repetitive in that way? Linnik et al. (2013) broached this topic. The manufacturing analogy is to decide what work can be done on any one of several specific lines vs. done off-line (e.g., workable backlog in the Last Planner System). A related system design question is: At what speed should the line (Parade) progress? The speed needed to match the project requirements may not be achievable when one or 
several bottleneck trades limit the pace for everyone. Adjustments to dependencies and sequencing of trades in the Parade and potential investments (e.g., alternative means and methods) then need to be considered to alleviate the bottleneck.

The approach we used is based on a mathematical concept, what Tommelein (in Dunnebier et al. 2014) called "work density" expressed in unit of time per unit of area. It is a trade-specific characteristic defined as follows: Given a certain work area, work density describes how much time a given trade will require to do their work in that area, based on the product design and the scope of work done by that trade for a given task in the schedule (thus depending on work already in place and work that will follow), the means and methods the trade will use to do their work while accounting for their crew's capabilities and crew size. Work density thus captures what will be done, by whom, when, where, and how. (Note that "work density" differs from "schedule density" defined in the context of change and delay analysis for productivity loss claims, e.g., Finke 2000. It also differs from workhours/location as used in LOB and LBMS because units of area are not necessarily the units of space that will be used in the TTP.).

\subsection{Collaborative TTP Method}

The 5 steps of the TTP method we formulated and tested on a pilot project (Dunnebier et al. 2014) and later used on projects similar in size and context, is based on the cycle of work structuring (Figure 1).

Step 1 - Collect Data: The researchers collected data from the team by construction phase several weeks before each phase's start. Tommelein and Ballard (2017) define "In the hierarchy of task breakdown, a phase is part of a project, the hinge point in regard to specifying what needs to be done vs. how to do it. It is a time period of a project, starting at a defined

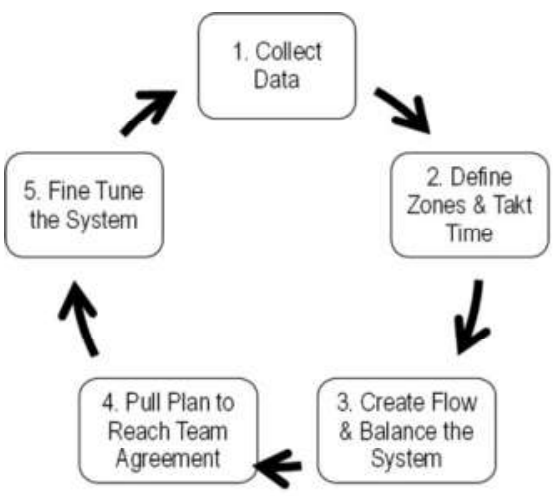

Figure 1: Process Steps for TTP (after Ballard and Tommelein 1999)

milestone, during which a specific group of activities is scheduled to be accomplished (e.g., building design, completion of foundations, erection of exterior walls, building dry-in), leading to the accomplishment of a defined end milestone. A phase comprises processes."

1.1 A description of the overall scope of work shown graphically, e.g., using drawings or BIM (Figure 2), and written in specifications to represent the product to be constructed. This product data is produced by designers prior to the start of construction, possibly reflecting input provided by contractors or suppliers.

1.2 A delimitation of the scope of work that will be done by each trade and, for each one, a description of the means and methods, sequence in which they want to work, and resources they plan to use.

On the pilot project, we collected this data from each trade foreman directly responsible for managing work (or supervisor, when the foreman was not yet identified or available). We asked them to bring a hard copy of the plan showing their scope (trade-specific plans look different from architectural plans, e.g., showing fabrication and installation detail), had them verbally describe the way(s) in which they wanted to approach their work while coloring-up the plan, using a different color for each chunk of work they expected to be 
able to complete in each successive 2-day time interval (shown in sequence on Figure 3). This time interval and coloring describe work density.

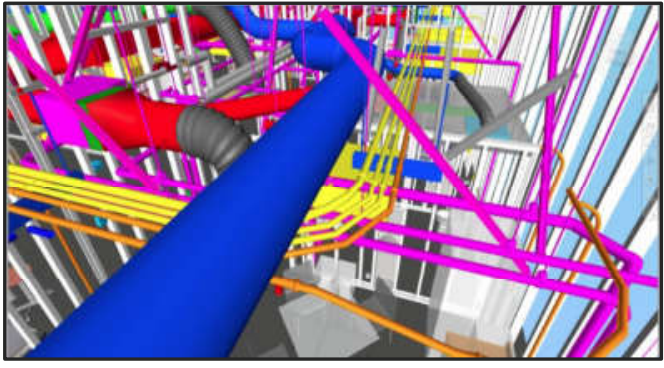

Figure 2: Building Information Model of Interior Overhead Space on Pilot Project

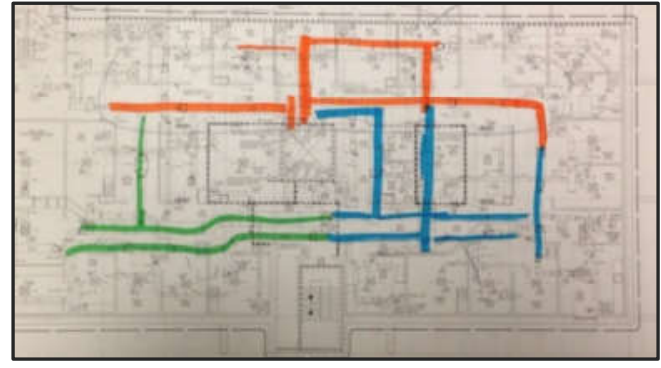

Figure 3: Input from Mechanical Trade using Work Chunks of 2-Day Takt, Sequenced Orange, Blue, then Green

A key part of the discussion is to have the foreman consider and articulate alternative approaches, and-if time permits-capture those in alternative color-ups. Clarity on a set of alternatives offers flexibility later in the TTP process, when the inputs from all trades get combined into the phase plan, and trade-offs may have to be made across trades.

Step 2 - Zones and Takt Time: The design of zones and takt is an iterative process.

2.1 After obtaining color-ups from each trade, the researchers overlaid these with a grid pattern to compute work density. Figure 4 schematically illustrates greater work density in increasingly darker colors for each trade (4.a mechanical, 4.b framing, and 4.c electrical). The number inside each grid cell is the time the trade needs to complete their work in the corresponding area (cell), given their assumed means and methods as well as crew sizing.

2.2 Subsequently, the researchers defined a zoning (a zone is a grouping of grid cells) to superimpose on the grid cells so that all space is covered and no zones overlap. Figure 4.d exemplifies one such zoning, with cells grouped into zones numbered [1] through [7].

The time each trade needs to complete their work in each zone is computed by adding up the numbers in the cells included in each zone. For example, in zone [5], mechanical needs $2+1=3$ time units, framing needs $1+2=3$, and electrical needs $6.8+0.9=7.7$. Figure 5 charts this data by zone, using a column for each trade. It shows peaks and valleys in work density. A perfectly balanced system would have columns of equal height.

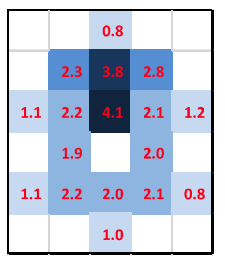

4.a Mechanical Trade

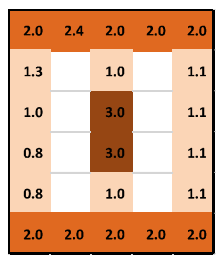

4.b Framing Trade

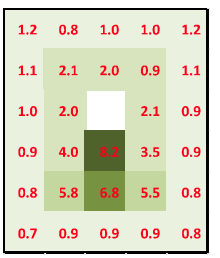

4.c Electrical Trade

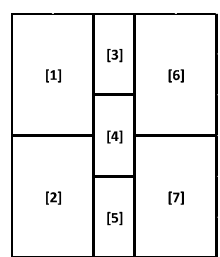

4.d Tentative Zoning

Figure 4: Work Density for Different Trades and Zoning

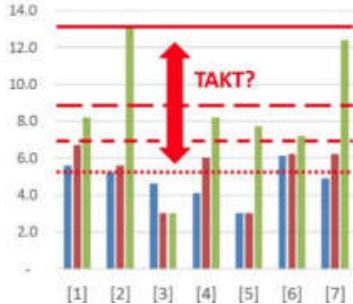

Figure 5: Time needed per Zone per Trade

2.3 Finally, the researchers chose a takt through trial-and-error (ongoing research is looking into how to systematize this step) by setting an upper limit on the time for trades to complete their work in each zone, allowing for some- but not too much underloading (capacity buffering). 
The researchers repeated steps 2.1, 2.2, and 2.3 while considering alternative crew sizes, means and methods, task allocation, and the like, so as to alter the work density and thereby make columns more even in height. This repetition ended when a takt-zoning combination was found to be satisfactory.

Step 3 - Create Flow and Balance the System: The researchers used the work flows shown in color-ups, to the extent possible, to illustrate how each trade's work would progress over time with work structured using a 2-day takt and Figure 4.d's zoning. They shared the resulting "schedule mock-ups" (Figure 6) with the trades to get feedback and buy-in.

6.a Mechanical Trade:

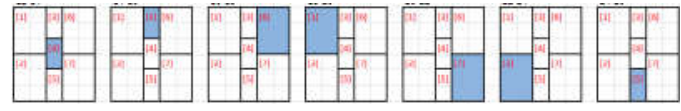

6.b Framing Trade:

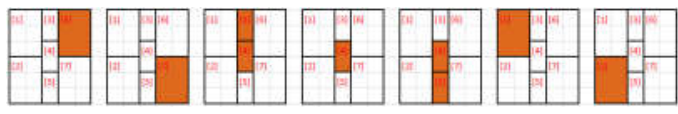

6.c Electrical Trade:

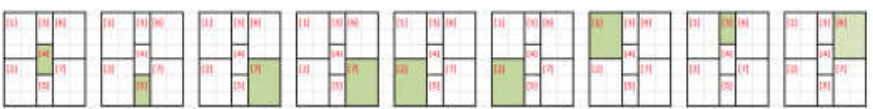

Figure 6: Patterns of Work Flow per Trade in 2-day Takt with Zoning

Steps 1, 2, and 3 prepared each trade to come to the phase planning meeting with their preferred plan and alternatives, as well as understanding of their plan flexibility based on advantages of doing work one way vs. another.

Step 4 - Pull Plan to Reach Team Agreement: At the team's phase planning session, the researchers explained to all what they had learned from the color-up sessions and shared their analysis of takt-zoning alternatives. The team's discussion that followed, on the timing of work within the milestones delimiting the phase, revealed concerns but also possibilities. E.g., considering the in-wall phase, the framer proposed to prefabricate wall sections to above-ceiling and convinced trade partners of the value of having all space to themselves to work fast, and then clear the way for everyone else. Shared understanding informed the subsequent pull planning effort, during which the trades meshed their patterns of work flow (Figure 7). The result was a takt plan, albeit not necessarily an optimal one since many zones are not worked in (zones left white are waiting on workers).

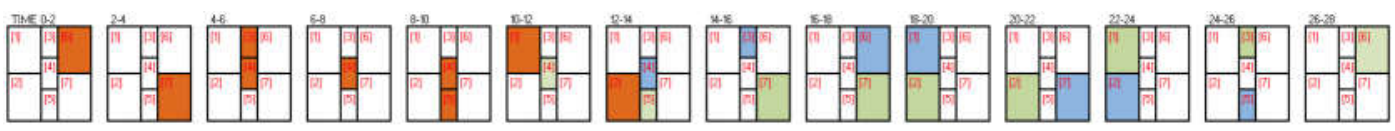

Figure 7: Meshed Patterns of Work Flow by 2-day Takt with Zoning

Step 5 - Fine Tune the System: Finally, trades added to this takted phase plan work to be done in areas other than those zoned (e.g., underfloor, on roof) as backlog to fill "time left." Dunnebier et al. (2014) and Frandson and Tommelein (2014) expand on the practical implementation of this takt plan. In summary, the work structuring done based on taktzoning resulted in phase plans that were successfully used with the Last Planner System.

\section{CONCLUSIONS}

This paper outlined the rationale and methodological steps for TTP piloted on a small healthcare project. Due to the non-repetitive nature of the work, the interdependence of scopes of work by different trades, and the small space available to work in, this TTP effort 
had to be collaborative. The means and methods that each trade could use on the project and their possible production speeds, could not have been known a priori. For this kind of TTP, detail is needed that is not readily available as book knowledge.

\section{ACKNOWLEDGMENTS}

The development of the method described in this paper was supported in part by members of the Project Production Systems Laboratory (P2SL) at UC Berkeley and in part by the National Science Foundation (NSF) under grant number CMMI-1563511. Any opinions, findings, and conclusions or recommendations expressed in this material are those of the authors and do not necessarily reflect the views of members of P2SL or NSF.

\section{REFERENCES}

Ballard, G. (1999). "Work Structuring." LCI White Paper No. 5, June, https://goo.gl/D96VMH

Ballard, G., Koskela, L., Howell, G., and Zabelle, T. (2001). "Production System Design: Work Structuring Revisited.” LCI White Paper No. 11, Jan. 24, https://goo.gl/d2h9ZY

Ballard, G. and Tommelein, I.D. (1999). “Aiming for Continuous Flow.” LCI White Paper3, March 5, 6 pp., https://goo.gl/eXNCBU

Binninger, M., Dlouhy, J., and Hagsheno, S. (2017). In: Proc. Lean \& Computing in Construction Congress (LC3), Vol. II (IGLC 25), Heraklion, Greece, forthcoming.

Dunnebier, D., Cleary, J., Galvez, M., Mizell, C., Mueller, K., Pease, J., Tommelein, I.D. (ordered alphabetically) (2014). "An Experiment in Takt Time." Presented at the $16^{\text {th }}$ Annual Congress of the Lean Construction Institute, San Francisco, CA, 7-10 October.

Finke, M.R. (2000). "Schedule Density as a Tool for Pricing Compensable Float Consumption." Cost Eng., June, 42 (6) 34-37.

Frandson, A.G., Seppänen O., and Tommelein, I.D. (2015). "Comparison Between Location Based Management and Takt Time Planning." Proc. 23 ${ }^{\text {rd }}$ Ann. Conf. of the International Group for Lean Construction (IGLC 23), Boston, MA, July, 3-12.

Frandson, A. and Tommelein, I.D. (2014). "Development of a Takt-time Plan: A Case Study.” ASCE, Proc. Constr. Research Congr. 2014, Atlanta, GA, 1646-1655.

Hopp, W.J. and Spearman, M.L. (2011). Factory Physics. $3^{\text {rd }}$ Ed., Waveland Press, Inc., Long Grove, IL, 720 pp.

Linnik, M., Berghede, K., and Ballard, G. (2013). "An Experiment in Takt Time Planning Applied to Non-Repetitive Work." Formoso, C.T. and Tzortzopoulos, P., Proc. $21^{\text {st }}$ Ann. Conf. Int'l. Group Lean Constr. (IGLC 21), Fortaleza, Brazil, 31 Jul-2 Aug., 609-618.

Lumsden, P. (1968). The Line-of-Balance Method. Pergamon Press Ltd., 71 pp.

Riley, D.R. and Sanvido, V.E. (1995). "Patterns of construction-space use in multistory buildings.” ASCE, J. Constr. Engrg. Mgmt., 121 (4) 464-473.

Tommelein, I.D. and Ballard, G. (2017). Lean Construction Glossary. Project Production Systems Laboratory (p2sl.berkeley.edu), Univ. of California, Berkeley, January, 71 pp.

Tommelein, I.D., Riley, D., and Howell, G.A. (1999). "Parade Game: Impact of Work Flow Variability on Trade Performance.” ASCE, J. Constr. Engrg. Mgmt., 125 (5) 304-310.

Tommelein, I.D. and Zouein, P.P. (1993). "Space Scheduling for Construction Progress Planning and Control." Proc. $10^{\text {th }}$ ISARC, Elsevier Sci. Pubs., 415-422.

Tsao, C.C.Y., Tommelein, I.D., Swanlund, E., and Howell, G.A. (2004). "Work Structuring to Achieve Integrated Product-Process Design.” ASCE, J. Constr. Engrg. Mgmt., 130 (6) 780-789. 